\title{
Como Perseu se defendeu de Medusa?
}

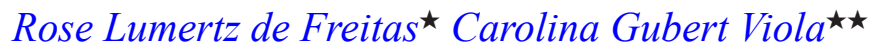

\begin{abstract}
RESUMO
Na psicanálise francesa, principalmente com Lacan, o conceito de falta passou a ser de grande importância. Ao que, então, perguntamos: o que é a falta? E quando esta falta? O que acontece? O que acontece quando o não especularizável não está excluído, se fazendo, assim, especular? Quando Perseu vai ao encontro de Medusa, guiando-se por sua imagem refletida em um espelho de bronze polido, segurado por Atena, como pôde este herói defenderse de Medusa? Qual foi a forma encontrada por ele para se defender da presença do objeto que introduz a dimensão do real nu?

Palavras-chave: falta; vazio; objeto a; angústia.
\end{abstract}

\section{How did Perseus protect himself against Medusa?}

\begin{abstract}
According to French psychoanalysis, specially with Lacan, the concept of lack turned to be an important formulation. But what is the concept of lack? What happens when the non-specularizable is not excluded and therefore turns into something specular? When Perseus runs into Medusa, guided by a bronze shield held by Atena, how did this hero defend himself from Medusa? What did he do in order to defend himself from the presence of the object that introduces the dimension of the real?
\end{abstract}

Keywords: lack; emptiness; object a; anguish.

^ Psicóloga. Graduação em Psicologia pela Universidade do Vale do Rio dos Sinos.

E-mail:rrlumertz@gmail.com

$\star \star$ Psicóloga. Mestre em Educação pela Universidade Federal do Rio Grande do Sul. Endereço: Universidade Federal do Rio Grande do Sul, Faculdade de Educação - Prédio 12201 - Av. Paulo Gama, s/n CEP 90046-900.

E-mail:ninavviola@gmail.com 
Através do Toro ${ }^{1}$ temos um claro exemplo de que aquilo que circunscreve um buraco, simultaneamente cria uma superfície. De acordo com a topologia, um buraco não é um furo numa superfície preexistente; buraco e superfície, aí, dão-se simultaneamente.

Aquilo que nos constitui, ao mesmo tempo nos escapa. Lacan (1998a, p.832) diz que o objeto $a$ é não especular. Por quê? Porque neste objeto há algo radicalmente estranho à imagem de si. O que funda e engendra, concomitantemente elide e barra. $\mathrm{O}$ buraco por onde escapa o objeto fundamentalmente perdido, buraco que o objeto $a$ imaginariamente obtura, indica algo latente que não passa pelo dizer. Este objeto, que é radical e definitivamente perdido, se constitui exatamente no momento de sua perda. O que está em jogo aí destaca-se pela sua inexistência inscrita. Mas o que isso quer dizer?

Em seu seminário Escrituras Lacanianas, Ivan Corrêa (1995, p. 09) propõe duas séries:

Série a: 01234

\section{Série b: 12345}

Essas duas séries não se correspondem. E, no que, então, elas diferem? $\mathrm{Na}$ "Série a", uma inexistência foi inscrita, o zero ocupou um lugar. E, segundo o psicanalista, uma inexistência, ou um lugar vazio (que o zero está representando), "não pode ser considerada como nada [...], no mundo simbólico é exatamente o vazio, o lugar vazio, a inexistência que pode produzir alguma coisa" (CORRÊA, 1995, p. 09), a saber: a representação.

O que falta a um número inteiro natural é o que faz surgir o seu sucessor: $n$ +1 . E este "1" é o lugar do zero, ou como Ivan Corrêa sugere, o lugar do Outro. ${ }^{2}$ "Então o que falta a cada inteiro natural é o um, o um marca do zero. O um é o que separa" (CORRÊA, 2007, p. 101). E essa separação - distância infinita - é análoga àquela entre dois significantes.

O elemento que funda os inteiros naturais é o zero, mas, quando se conta os inteiros naturais o que advém é a cifra do simbólico. Ivan Corrêa (2001, p. 89) nos propõe a seguinte questão: "Mas o que inscreve que um real exista?". A resposta vem do mesmo: "o simbólico como tal" (CORRÊA, 2001, p. 89).

Retomando a ideia de objeto $a$, um sujeito que detém uma imagem individualizada de si não perde sua relação com esse objeto, ele simplesmente é incapaz de reconhecê-lo, isto porque não há conformidade entre aquilo que causa o desejo ${ }^{3}$ e a autoidentidade, mas uma distância intransponível. O que acontece quando Narciso observa que a imagem refletida tratava-se dele, que ele era a sua imagem? Se não temos a mediação da imagem especular, ${ }^{4}$ o que pode acontecer frente a uma relação direta entre o sujeito e o Outro? O que significa estar ausente o eixo imaginário que faz, então, o obstáculo entre o sujeito e o Outro? Sabemos que a não inscrição de uma ausência é significativa. 
Ainda segundo Corrêa (2007, p. 134), o que está em jogo na angústia não é "um perigo que se dirige à vida, [...] mas àquilo que serve para o sujeito ser representado, isto é, esse sistema significante que assegura sua relação ao Outro". Ainda que a angústia assinale a iminência da presença, o objeto $a$ não o é se não ausente, velado, faltante e inapreensível. ${ }^{5}$ A angústia - este sinal de vacilo na relação entre o sujeito e o objeto $a$ - não é sem objeto; não se pode dizer de que objeto se trata, uma vez que o seu caráter é ser errático, não especular.

Annie Anzieu (1992) nos lembra a passagem em que o rei David estava sendo perseguido por seus inimigos. Quando pede ajuda a Deus, este pôs o rei dos hebreus diante de um antro ${ }^{6}$ disfarçado por uma teia de aranha. "David atravessou a teia e se abrigou no côncavo. Os inimigos logo o seguiram, mas, encontraram reconstituído o véu aracnídeo diante do orifício, afastando qualquer suspeita de uma passagem recente" (ANZIEU, 1992, p.15).

O que é ôntico, na função do inconsciente, é a fenda por onde esse algo, cuja aventura em nosso campo parece tão curta, é por um instante trazida à luz - por um instante, pois o segundo tempo, que é de fechamento, dá a essa a apreensão um caráter evanescente (LACAN, 1998b, p.35).

No campo da furação dos significantes, "a fantasia é um torniquete" (TYSZLER, 2007, p.102), uma proteção frente ao enigma do desejo humano. O objeto do desejo do Outro especifica um gozo para sempre indizível. Este objeto topológico pequeno $a$ delimita um furo, através do qual o real encontra uma consistência estável. Ou ainda, no campo das imaginarizações dos objetos de substituição, a fantasia nos guia mascarando o real dos objetos.

E haveria diferença entre falta e vazio? Menos um e zero não são a mesma coisa. O nada, diz Ivan Corrêa (2001, p. 53), "é exatamente a não-existência, que é diferente da falta. Na falta trata-se de algo a menos. E quando se fala de um buraco como sendo nada, não é muito exato, porque para se ter buraco, necessitase de ter pelo menos uma borda". Assim, topologicamente falando, há buraco porque há borda; o buraco é constituído por uma borda.

O zero, marca de real, de não existência, é, diz Ivan Corrêa (1995, p. 8), um "tropeço". Na literalidade entre Tropos e tropeço, o psicanalista lembra que, para os gregos, Tropos ${ }^{7}$ implicava um desvio. Medusa, cabe lembrar, foi sempre pictoricamente representada de frente, ${ }^{8}$ jamais de viés (VERNANT, 2001). Nesse sentido, diz Lacan (1998b, p. 100): "Uma estrela de quinta ou sexta grandeza, se vocês quiserem vê-la [...] não a fixem diretamente. E precisamente olhando um pouquinho ao lado que ela nos pode aparecer".

E o conjunto vazio? ${ }^{9}$ Inscreve a falta ou o nada? O conjunto vazio inscreve o nada, a não existência, que quando escrita, tem seus efeitos. Do mesmo modo o Outro, que não existe, literalmente. O que especifica um conjunto não é que este seja um todo, mas um buraco. Se nada pertence a zero - nome da não existência -, por intermédio de Cantor fica possível pensar que o conjunto vazio faz uma borda que enseja a inscrição. 
Vernant (2001) nos ressalta algo: a face de medusa é uma máscara. Tyszler, por sua vez, nos recorda uma passagem de Lévi-Strauss (1975, apud TYSZLER, 2007, p. 111) em seu célebre Les sentiers de la création: "Como um mito, uma máscara nega tanto quanto afirma; ela não é feita somente do que ela diz ou acredita dizer, mas do que ela exclui".

E o que é que se exclui? Como contamos o inteiro natural 8? Sete mais um. E o que é o "mais um"? Justamente o lugar do zero. Agora, quando temos o inteiro natural 8 , aí já não temos mais o zero. Por quê? Porque quando chegamos ao 8, o zero é expelido da cadeia numérica.

Ora, o que é que se exclui? O sujeito do inconsciente. Este é excluído da cadeia do significante, tal como a verdade, ${ }^{10}$ que "logo que vem à luz, perde-se no saber" (CHEMAMA; VANDERMERSCH, 2007, p. 362). O sujeito, uma vez engendrado na linguagem, opera com uma incerteza irredutível quanto ao seu desejo. Entre enunciado e enunciação há uma divisão intransponível, restando um "semidizer".

$\mathrm{Na}$ tese principis de Lacan, um significante ${ }^{11}$ é aquilo que representa o sujeito para outro significante: "Esse significante, portanto, será aquele para o qual todos os outros significantes representam o sujeito: ou seja, na falta desse significante, todos os demais não representariam nada" (1998a, p.833).

E o que é o nada? O nada é aquilo que não existe. Segundo o princípio de identidade, segundo o qual o que é, é, o zero é o nada - uma vez que inexiste aquilo que não seja idêntico a si. O significante, por sua vez, não é idêntico a si, ele sempre remete o sujeito a um outro significante. Lévi-Strauss (1975, apud TYSZLER, 2007, p. 111) diz que:

[...] uma máscara não existe em si; ela supõe, sempre presentes a seu lado, outras máscaras reais ou possíveis que teríamos podido escolher para substituí-la. [...] Uma máscara não é de saída aquilo que ela representa, mas aquilo que ela transforma, ou seja, escolhe não representar.

E o que pode nos acontecer se olharmos para a máscara que é Medusa? Podemos perder a dimensão do que há em nós de inacessível (DIDIER-WEILL, 1997, p. 279). Um significante, assim, "significa um sujeito para outro significante, mas não significa o real como tal" (FINK, 1998, p. 143).

Vernant (1985, p. 105) diz que Medusa "em vez de nos devolver apenas a aparência de nosso próprio rosto, de refratar nosso olhar, representaria, em sua careta, o horror terrificante de uma alteridade radical [...] transformando-nos em pedra". Quando o olhar se vê, isto implica em uma cegueira, em um aniquilamento do sujeito. Se, um significante é aquilo que lança o sujeito para outro significante, Medusa, por sua vez, imobiliza, transforma-os em pedra. 
O olhar é esse objeto perdido, e repentinamente reencontrado [...] e o que é que o sujeito procura ver? O que ele procura ver, saibam bem disto, é o objeto enquanto ausência. [...] O que se olha é aquilo que não se pode ver (LACAN, 1998b, p.173).

Lacan diz que o significante "só pode ser um traço que se traça por seu círculo, sem poder ser incluído nele" (1998a, p.833). Trata-se aí de "um antes que surge com a rasura do depois" (CORRÊA, 2007, p.53).

É somente quando o que fundava a possibilidade da existência é passado, até mesmo trespassado, que se revela para ele [sujeito] a descoberta, como tal, da existência desta incógnita sobre a qual ele nada sabia, cuja existência nada podia fazê-lo medir, senão sua própria desaparição (DIDIER-WEILL, 1994, p. 43).

Ainda, Lacan (1998a, p. 833) diz que este significante é "simbolizável pela inerência de um (-1) no conjunto dos significantes. Como tal, esse significante é impronunciável, porém não a sua operação".

Ocorre que, com Frege, podemos atribuir ao zero um duplo entendimento: "o zero como não existência e o zero como conceito da não existência" (CORREA, 2007, p. 99). Ou seja, o zero como inscritível e o zero como ausência radical, insignificável. Lidamos aí com duas figuras, distintas, de negatividade: o vazio (ao qual indexamos o zero) e a falta (a qual corresponde o menos um). E, novamente, no que vazio e falta se diferenciam?

Ao real, se considerado em si, nada falta. ${ }^{12}$ Fernando Pessoa (1976, p. 132) nos questiona: "Quando penso que vejo, quem continua vendo enquanto estou pensando?". Será que aqueles que cruzam com o olhar de Medusa poderiam responder a esta pergunta? Não, pois "o vazio, se encontrado, não é uma falta; ele não se torna uma a não ser na medida em que o significante o designe como falta de alguma coisa nesse lugar" (CHEMAMA; VANDERMERSCH, 2007, p. 143).

O vazio, em seu estatuto de real impronunciável, recebe, uma vez inscrito o zero, uma marca do possível através do contorno significante da absoluta negatividade. "A possibilidade da ausência, eis a segurança da presença" (LACAN, 2005, p. 64).

Do nada absolutizado ao contorno do vazio: disto o sujeito nada pode dizer ou imaginar. Assim como o mito, ${ }^{13}$ que nos remete à ideia de uma origem jamais alcançável, impassível de representação.

Nesse sentido, a angústia "não é sem objeto" (LACAN, 2005, p.101); pas sans, "L'angoisse n'est pas sans object", não desprovido de. Não desprovido do que? De objeto?

Nas palavras de Lacan (2005, p. 88), “a angústia é esse corte - esse corte nítido sem o qual a presença do significante, seu funcionamento, seu sulco no real, é impensável; é esse corte a se abrir". "A angústia é quando aparece [...] o que já estava ali, muito mais perto, em casa, Heim. [...] O que é Heim, o que é Geheimnis [segredo, mistério], nunca passou pelos desvios [...]. Manteve-se unheimlich" (LACAN, 2005, p. 87). 
Quando essa imagem especular que temos diante de nós, que é nossa altura, nosso rosto, nosso par de olhos, deixa surgir a dimensão de nosso próprio olhar, o valor da imagem começa a se modificar - sobretudo quando há um momento em que o olhar que aparece no espelho começa a não mais olhar para nós mesmos. Initium, aura, aurora de um sentimento de estranheza que é porta aberta para a angústia (LACAN, 2005, p. 100).

A fim de compreender a relação do objeto com a angústia, Lacan (2005) nos remete ao texto $O$ estranho de Freud (1996[1919]). Nessa perspectiva, Freud (1996[1919], p. 264) comenta, a propósito de sua extensa pesquisa sobre o significado de heimlich e unheimlich, que "heimlich é uma palavra cujo significado se desenvolve na direção da ambivalência, até que finalmente coincide com o seu oposto, unheimlich. Unheimlich é, de um modo ou de outro, uma subespécie de heimlich".

É o que ocorre com, uma vez que esta também comporta isso que é coincidente com o seu oposto. Segundo Vernant (2001, p.75),

Gorgó $^{14}$ traduz outro aspecto do sagrado: o sagrado absolutamente proibido, [...], um sagrado tão perfeitamente puro, tão afastado da vida humana que pode surgir como horrível e assustador - qualquer contato com ele nos entrega à mácula irremediável ou nos arranca à condição humana.

Unheimlich, estranho familiar; presente, mas estranho, já que o sujeito aí não se reconhece. $\mathrm{O}$ real recortado pelo significante, sob a forma de objeto $a-$ resto não significável -, está presente na angústia, ainda que seja velado no que é.

Com o êxito da imagem em encobrir o vazio, a imagem refletida no espelho opera com um invisível. O sujeito não pode ter uma relação com o objeto $a$ se não por uma mediação imaginária; a imagem especular veste o objeto não capturável no espelho. Nos diz Lacan (1998a, p. 832): "É a esse objeto inapreensível no espelho que a imagem especular dá a sua vestimenta". A imagem especular reveste o objeto inalcançável. E o que resta sob a vestimenta quando ela é retirada ${ }^{15} \mathrm{Nada}$, senão este resto a-especular (CZERMAK, 1991, p. 141).

O desvelamento revela a ausência daquilo que é desvelado. Segundo Vernant (2001, p. 73), “os gregos expressavam pela máscara de Gorgó [...] o resto frente ao qual só podemos permanecer calados e paralisados".

Lacan vai jogar muitas vezes com a função velatória em jogo na revelação. Com efeito, ensina que sempre se trata, mediante a escansão, de uma re-velação - a maneira pela qual se desvela alguma coisa imediatamente se volta a velar. [...] Mediante a pontuação de que a revelação é um voltar a velar, ele logra escindir a representação imagética - aparentemente mostrativa -, que se dá-a-ver, do terreno do significante, elusivo e inapreensível (HARARI, 2006, p. 80).

A angústia, por fim, "não é o sinal de uma falta, mas de algo que devemos conceber num nível duplicado, por ser a falta de apoio dada pela falta" (LACAN, 2005, p. 64). 
No campo do Outro algo falta. O sujeito, na sua relação com o Outro, se inscreve como um quociente, isto é, como um resultado de uma marca significante, na qual há um resto irracional e enigmático denominado objeto $a$. Nos diz Lacan (2005, p. 36):

No começo vocês encontram A, o Outro originário como lugar do significante e S, o sujeito ainda inexistente, que tem que se situar como determinado pelo significante. [...] Há, no sentido da divisão [subjetiva do advento do sujeito], um resto, um resíduo [a operação significante é incompleta]. Esse resto, esse Outro derradeiro, esse irracional, essa prova e garantia única, afinal, da alteridade do Outro é o $a$.

Segundo Vernant (2001, p. 84), o sujeito é extrovertido: ele se olha de fora.

E quando inexiste a falta? O que acontece? O que acontece quando o não especularizável não está excluído, se fazendo, assim, especular? Afinal, como Perseu se protegeu de Medusa? Qual foi a forma encontrada por ele para se defender da presença do objeto que introduz a dimensão do real nu?

Perseu vai ao encontro de Medusa não a fitando diretamente, mas de viés: guiou-se por sua imagem refletida em um escudo de bronze - segurado por Atena -, polido a ponto de refletir. Olhando para o espelho, Perseu não viu seus próprios olhos, mas sim Medusa.

\section{Notas}

${ }^{1}$ Objeto topológico que nos remete a uma relação contínua entre o que há de mais íntimo e mais estranho ao sujeito.

2 “o Outro não é um sujeito, é um lugar ao qual nos esforçamos - diz Aristóteles - por transferir o saber do sujeito [...] mas isso não quer absolutamente dizer que o sujeito não saiba um tico a mais sobre o assunto em questão. Ele não tem perturbação, se posso dizer, a não ser em função de uma suposição indevida, a saber, que o Outro saiba, que haja um saber absoluto, mas o Outro sabe disso ainda menos que ele, pela simples razão, justamente, de que ele não é um sujeito. $\mathrm{O}$ Outro é o depositário dos representantes representativos dessa suposição de saber, e é isso que chamamos de inconsciente, na medida em que o sujeito perdeu-se, ele mesmo, nesta suposição de saber" (LACAN, 1961-62, p. 24).

${ }^{3}$ A propósito, "A perda que a captura na linguagem implica, engendra uma incerteza irredutível para o sujeito quanto ao seu desejo. Ele está condenado a buscá-lo sem nunca encontrá-lo" (MELMAN, 2008, p. 201).

${ }^{4} \mathrm{O}$ sujeito não pode ter uma relação direta com o objeto $a$, a não ser através de uma mediação imaginária. A imagem especular dá uma roupagem ao objeto não capturável no espelho.

5 "Já fiz uso desse não é sem na formulação que lhes apresentei a respeito da relação entre o sujeito e o falo: ele não é sem tê-lo. Essa relação do não ser sem ter não significa que saibamos de que objeto se trata. Quando digo Ele não é sem recursos, Ele não é sem astúcia, isso quer dizer que, pelo menos para mim, seus recursos são obscuros, sua astúcia não é comum” (LACAN, 2005, p. 101).

${ }^{6}$ A propósito, nos diz Lacan (1998b, p. 138): "Podemos conceber o fechamento do inconsciente pela incidência de algo que desempenha o papel de obturador - o objeto $a$, chupado, aspirado, ao orifício da nassa". "Se o inconsciente é aquilo que se tranca uma vez que isso se abre, segundo uma pulsação temporal, se a repetição, por outro lado, não é simplesmente estereotipia da conduta, mas repetição em relação a algo de sempre faltoso, vocês vêem desde já que a transferência [...] só poderia ser, por si mesma, uma via precária" (LACAN, 1998b, p. 136).

${ }^{7}$ Desvio, equívoco na linguagem que produz uma figura retórica.

${ }^{8}$ Com exceção dos gregos arcaicos. 
${ }^{9}$ Segundo a teoria dos conjuntos, postula-se a existência de um conjunto vazio, subconjunto de qualquer conjunto.

10 “ [...] se a verdade desvela e esconde ao mesmo tempo, isso não se deve ao que seria da ordem do ser, isso se deve à falta a ser que determina o significante, ao real que ele instala" (CHEMAMA; VANDERMERSCH, 2007, p. 386).

${ }^{11}$ É necessário esclarecer este termo "significante". Para que haja sujeito (\$), é necessário a introdução de um significante radical, primeiro. Segundo Bruce Fink (1998, p. 143), "o "desaparecimento" desse primeiro significante é necessário para a instituição da ordem do significante como tal [...]. O status desse primeiro significante excluído é obviamente muito diferente do de outros significantes".

12 "Em Le désir et son interprétation (1959), [Lacan] entrelaça os três registros da subjetividade : real, simbólico e imaginário, para especificar as diferentes categorias da falta que afetam um sujeito" (CHEMAMA; VANDERMERSCH, 2007, p. 144). A saber: I) frustração: falta imaginária, cujo agente é simbólico e cujo objeto é real; II) castração: falta simbólica; e III) privação: falta real; o significante aqui opera de forma velada.

13 " $\mathrm{O}$ mito tem duas dimensões - tem esse aspecto de algo que nunca vou atingir, mas por outro lado tem algo que está na ordem de que sem mitos eu não posso viver. [...] É o que se produz em cada um de nós que entramos no reino da palavra. Somos todos atravessados pelo mito e pela questão da origem, ou pelo mito da origem. Origem sempre impossível de representar" (CORRÊA, 2001, p. 23).

${ }^{14}$ Gorgó, plural de Gorgones. Forcis e Cetó tiveram três filhas monstruosas: "Euríale (Caminhante a Passos Largos), Estenó (Poderosa) e Medusa (Rainha), [...] chamada simplesmente de Gorgó" (KURY, 2003, p. 165).

${ }^{15}$ Lacan (2003, p. 201), a propósito de sua homenagem a Lol V. Stein de Marguerite Duras: "O que ser embaixo dela?.[O que ser sob?] O que lhe resta agora é o que diziam de você quando você era pequena, que você nunca estava exatamente ali".

\section{REFERÊNCIAS}

ANZIEU, A. A mulher sem qualidade. São Paulo: Casa do psicólogo, 1992.

CHEMAMA, R; VANDERMERSCH, B. Dicionário de psicanálise. São Leopoldo: Unisinos, 2007.

CORRÊA, I. Escrituras lacanianas. Recife: Centro de Estudos Freudianos, 1995.

CORRÊA, I. A Psicanálise e seus paradoxos: seminários clínicos. Salvador: Ágalma; Recife: Centro de Estudos Freudianos, 2001.

CORRÊA, I. Nós do inconsciente. Recife: Centro de Estudos Freudianos, 2007.

CZERMAK, M. Paixões do objeto. Porto Alegre: Artes Médicas, 1991.

DIDIER-WEILL, A. Inconsciente freudiano e transmissão da psicanálise. Rio de Janeiro: J. Zahar, 1994.

DIDIER-WEILL, A. Os três tempos da lei: o mandamento siderante, a injunção do supereu e a inovação musical. Rio de Janeiro: J. Zahar, 1997.

FINK, B. O sujeito lacaniano: entre a linguagem e o gozo. Rio de Janeiro: J. Zahar, 1998. 
FREUD, S.O Estranho [1919]. In: Uma neurose infantil e outros trabalhos. In: . Obras Psicológicas Completas de Sigmund Freud. Rio de Janeiro: Imago, 1996. v. 17, p. 233-270. Edição Standard Brasileira.

HARARI, R. Por que não há relação sexual? Rio de Janeiro: Companhia de Freud, 2006.

KURY, M. Dicionário de mitologia grega e romana. Rio de Janeiro: J. Zahar, 2003.

LACAN, J. Subversão do sujeito e dialética do desejo no inconsciente freudiano. In: . Escritos. Rio de Janeiro: J. Zahar, 1998a. p. 807-842

LACAN, J. O Seminário: os quatro conceitos fundamentais da psicanálise [19631964]. Rio de Janeiro: J. Zahar, 1998b. Livro XI.

LACAN, J. Homenagem a Marguerite Duras pelo Arrebatamento de Lol V. Stein. In: . Outros Escritos. Rio de Janeiro: J. Zahar, 2003. p.198-205.

LACAN, J. O Seminário: a angústia [1962-1963]. Rio de Janeiro: J. Zahar, 2005. Livro X.

LÉVI-STRAUSS, C. La Voie des Masques: les sentiers de la création. Genève: Albert Skira, 1975

MELMAN, C. O homem sem gravidade: gozar a qualquer preço. Rio de Janeiro: Companhia de Freud, 2008.

PESSOA, F. Obra poética. Rio de Janeiro: J. Aguilar, 1976.

TYSZLER, J. A Fantasia, do roteiro imaginário à lógica de um objeto. Revista Tempo Freudiano, Rio de janeiro, n. 8, 101-115, set. 2007.

VERNANT, J. A morte nos olhos, figuração do outro na Grécia Antiga: Ártemis e Gorgó. Rio de Janeiro: J. Zahar, 1985.

VERNANT, J. Entre mito e política. São Paulo: Universidade de São Paulo, 2001.

Recebido em: 06 de julho de 2010

Aceito em: 14 de março de 2012 
